\title{
HUBUNGAN FAKTOR INTERNAL DAN EKSTERNAL BIDAN DALAM PELAYANANANTENATAL DI PUSKESMAS KOTA PADANG
}

\author{
Silvia Adi Putri ${ }^{1}$ \\ Fakultas Kesehatan dan MIPA, Universitas Muhammadiyah Sumatera Barat, Jln Raya Bukittinggi \\ Payakumbuh Km 14, Nagari Tabek panjang, Kecamatan Baso, Kabupaten Agam, Sumatera Barat \\ Email : Silviaadiputri86@gmail.com
}

ABSTRAK

Keberhasilan upaya kesehatan ibu dapat dilihat dari indikator angka kematian ibu, Jumlah kematian ibu pada tahun 2017 meningkat dari tahun 2016 yaitu dari 17 orang menjadi 20 orang. Dalam upaya menurunkan angka kematian ibu tersebut perlu diupayakan pelayanan antenatal yang optimal. Tujuan dari penelitian ini adalah untuk melihat hubungan faktor internal dan eksternal bidan dengan pelayanan antenatal di Puskesmas kota Padang tahun 2017.

Jenis penelitian ini adalah kuantitatif dengan desain penelitian cross sectional Study. Populasi dalam penelitian ini adalah seluruh bidan yang bertugas di ruangan KIA di Puskesmas Rawatan kota Padang yaitu 40 orang. Teknik pengambilan sampel adalah total sampling. Pengumpulan data dilakukan pada bulan November 2017 sampai bulan Januari 2018. Analisa data adalah univariat, bivariat dan multivariat.Hasil penelitian lebih dari separo responden telah melaksanakan pelayanan antenatal sesuai standar, tidak pernah mendapatkan pelatihan, bersikap baik, lama kerja lama, komitmen atasan kurang baik, penerimaan lingkungan kurang baik, dan separo responden dengan motivasi baik. Terdapat hubungan antara sikap bidan, motivasi, komitmen atasan dan penerimaan lingkungan dengan pelayanan antenatal, dan tidak terdapat hubungan antara pendidikan, pelatihan, dan lama bekerja dengan pelayanan antenatal.Disimpulkan faktor internal yang berhubungan dengan pelayanan antenatal adalah sikap, motivasi, faktor eksternal yang berhubungan dengan pelayanan antenatal komitmen atasan dan penerimaan lingkungan. Disarankan kepada pimpinan puskesmas untuk berkomitmen yang tegas untuk terlaksananya pelayanan antenatal, untuk bidan disarankan untuk bersikap, motivasi baik dalam melaksanakan pelayanan antenatalsesuai stadar.

Kata kunci : Faktor internal, faktor eksternal dan pelayaan antenatal

\section{ABSTRACT}

The success of maternal health efforts can be seen from the indicators of maternal mortality rate The number of maternal deaths increases from 17 people in 2015 to 20 people by 2016. To reduce maternal mortality, optimal antenatal care is needed. The purpose of this study is to see the relationship between internal and external factors of midwives with antenatal care in community health centers of Padang city in 2017.This research is of quantitative type with cross sectional study desig. Population in this research includes all midwife who served in maternity wards at community health centers of Padang city, amounting to 40 people. The sampling technique used herein is total sampling. Data collection was conducted in November 2015 until January 2016. Data analysis are univariate, bivariate and multivariate.

According to the results of the study, more than half of the respondents have provided antenatal care up to standards, were never professionaly trained, were nice, had been working for long enough, lacking boss commitment, were not well-received by their work environment, and half of respondents have good motivation. There is a correlation between the midwife's attitudes, motivation, boss commitment and environmental acceptance with antenatal care, and no correlation between education, training, and length of service with antenatal care.It is concluded that internal factors related to antenatal care are attitudes, motivation, external factors related to antenatal care, boss commitment and environmental acceptance. Community health center leaders are advised to truly commit to the implementation of antenatal care, while midwives are advised to adopt good behavior 
and motivation in implementing antenatal care according to the applicable standards. Keywords: Internal Factor, External Factor and Antenatal Care

\section{PENDAHULUAN}

Pendahuluan Pembangunan kesehatan diarahkan untuk meningkatkan kesadaran, kemauan, dan kemampuan hidup sehat bagi setiap orang agar peningkatan derajat kesehatan masyarakat yang setinggi- tingginya dapat terwujud. Pembangunan kesehatan diselenggarakan dengan berdasarkan pada perikemanusiaan, pemberdayaan dan kemandirian, adil dan merata, serta pengutamaan dan manfaat dengan perhatian khusus pada penduduk 
rentan, antara lain ibu, bayi, anak, lanjut usia (lansia) dan keluarga miskin ${ }^{(1)}$

$$
\text { Pelaksanaan dari Millenium }
$$

Development Goals (MDGs) telah berakhir pada tahun 2015. Dimana pencapaian MDGs tersebut masih belum tercapai adalah menurunkan angka kematian ibu melahirkan, menurunkan penyebaran HIV dan AIDS serta akses air bersihndan sanitasi dasar. MDGs akan dilanjutkan dilanjutkan dengan Sustainable Development Goals (SDGs) hingga tahun 2030 yang lebih menekankan kepada 5P yaitu : People, Planet, Peace, Prosperity dan Partnership. Pelaksanaan SDGs akan diarahkan kepada kewajibankewajiban untuk melanjutkan dan memperluas keberhasilan MDGs. Mengamati inklusifitas dan proses penyusunannya SDGs diharapkan mampu membangun diatas pondasi yang sudah dibuat MDGs. Intergrasi antar dimensi yang berbeda dari pembangunan yang berkelanjutan, tidak hanya terkait pencapaian target, namun juga penting dipastikan upaya bersama ditingkat nasional untuk memasukkan SDGs dalam agenda pembangunan nasional dari perencanaan sampai pelaksanaan. ${ }^{(2)}$

Seluruh isi kesehatan dalam SDGs diintegrasikan dalam satu tujuan yakni tujuan nomor 3, yatu menjamin kehidupan yang sehat dan mendorong kesejahteraan bagi semua orang disegala usia. Selain permasalahan yang belum tuntas ditangani diantaranya yaitu upaya penurunan Angka Kematian Ibu (AKI) dan Angka Kematian Bayi (AKB), pengendalian penyakit HIV/AIDS, TB malaria serta peningkatan akses kesehatan reproduksi (termasuk KB), terdapat hal-hal baru yang menjadi perhatian, yaitu : 1)Kematian akibat penyakit tidak menular (PTM); 2) Penyalahgunaan narkotika dan alcohol; 3) kematian dan cedera akibat kecelakaan lalu lintas; 4) Univerasal Health Coverage; 5) Kontaminasi dan polusi air, udara dan tanah; serta penanganan krisis dan kegawat daruratan. . (2)

Penurunan AKI merupakan indikator keberhasilan derajat kesehatan suatu wilayah. Untuk itu pemerintah berupaya bahu membahu membuat berbagai strategi untuk akselerasi menurunkan Angka Kematian Ibu. Kematian Ibu sangat ditunjang dengan pelaksanaan ANC yang berkualitas dan terpadu, Kelas Ibu Hamil, Persalinan yang aman serta pemantauan kasus kematian maternal yang akurat sehingga bisa menggambarkan penyebab kematian yang nantinya bisa menjadi bahan pembelajaran. ${ }^{(3)}$

Dalam upaya menurunkan angka kematian ibu tersebut perlu diupayakan pelayanan Antenatal yang optimal. Tujuan utama asuhan antenatal adalah untuk memfasilitasi hasil yang sehat dan positif bagi Ibu maupun bayinya dengan cara membina hubungan saling percaya dengan Ibu, mendeteksi komplikasi-komplikasi yang dapat mengancam jiwa, mempersiapkan kelahiran, dan memberikan pendidikan.

Asuhan antenatal penting untuk menjamin agar proses alamiah tetap berjalan normal selama kehamilan. Kehamilan dapat berkembang menjadi masalah atau komplikasi setiap saat. Sekarang ini secara umum sudah diterima bahwa setiap kehamilan membawa resiko bagi $\mathrm{Ibu}^{(3)}$

WHO memperkirakan bahwa sekitar 15\% dari seluruh wanita yang hamil akan berkembang menjadi komplikasi yang berkaitan dengan kehamilannya serta dapat mengancam jiwanya. ${ }^{(4)}$

Menurut data dari Departemen Kesehatan RI, dari 33 Propinsi di Indonesia Sumatera Barat menduduki peringkat ke 18 terendah mencapaian K1 pada tahun 2014 yaitu sebanyak 58.93\%, dan cakupan K4 menduduki peringkat ke 16 terendah yaitu (49.35) . Pada tahun 2013 pencapaian K1 sebanyak $102.47 \%$ dan K4 sebanyak $89.64 \%$. $^{(5)}$

Data yang diperoleh dari Departemen Kesehatan RI angka kematian ibu di Sumatera Barat pada tahun 2014 mengalami peningkatan yang cukup tinggi yaitu pada bulan januari sebanyak 8 orang, Februasi 14 orang, Maret sebanyak 25 orang, April sebanyak 36 orang, Mei sebanyak 41 orang, Juni sebanyak 61 orang, Juli sebanyak 52 orang, dan agustus sebanyak 40 orang. ${ }^{(6)}$

Angka Kematian Ibu (AKI) adalah banyaknya kematian perepuan pada saat 
hamil atau pada saat 42 hari sejak terminasi kehamilan tampa memandang lama dan tempat persalinan, yang disebabkan karena kehamilannya atau pengelolaannya dan bukan karna sebab-sebab lain, per 100.000 kelahiran hidup. AKI merupakan salah satu indikator dari derajat kesehatan juga merupakan salah satu target yang telah ditentukan dalam tujuan pembangunan millennium (MDGs) tahun 2015 yaitu tujuan menurunkan Agka Kematian Ibu (AKI) hingga 3/4 dalam kurun waktu 1990-2015 dimana ditargetkan AKI pada tahun 2015 sebesar 202/100.000 kelahiran hidup. ${ }^{(7)}$

Kasus kematian ibu meliputi kematian ibu hamil, ibu bersalin dan ibu nifas. Di Kota Padang pada tahun 2016, kasus kematian ibu berjumlah 20 0rang, naik jika dibandingkan tahun 2015 (17 orang) Tren kasus kematian ibu setiap tahun bervariasi, secara umum mengalami naik turun. ${ }^{(2)}$ Pada tahun 2013 jumlah kematian Ibu hamil sebanyak 4 orang, jumlah kematian Ibu bersalin 9 orang, dan jumlah kematian Ibu nifas sebanyak 2 orang. ${ }^{(8)}$

Data yang diperoleh dari bidang pelayanan kesehatan Dinas Kesehatan Kota Padang tahun 2013 dari 20.043 Ibu hamil, perkiraan Ibu hamil dengan komplikasi kebidanan 4.009 (20\%) Ibu hamil, dan hanya 1.490 (37.5\%) yang ditangani kompikasi kebidanannya. Jumlah bayi lahir hidup dibanding Ibu hamil adalah 17.767 (88.6\%) sedangkan perkiraan neonatal komplikasi 2.665 bayi (15\%) dengan penanganan komplikasi neonatal 597 bayi (22.1\%) sedangkan sisa Ibu hamil yang mengalami komplikasi mencari pengobatan sendiri tampa melaporkan ke Dinas Kesehatan. ${ }^{(8)}$

Kematian ibu disebabkan karena berbagai komplikasi, diantaranya Jumlah Ibu yang meninggal di Kota Padang adalah sebanyak 16 orang dengan kasus pendarahan 5 orang $(31.25 \%)$, hipertensi 7 orang $(43.75 \%)$ dan infeksi 1 orang ( $6.25 \%$ ) dan 3 orang karena kecelakaan, hepatitis dan thalasemia. Keadaan bayi saat lahir, 17.767 orang lahir hidup dan kematian neonatal sebanyak 73 orang, kasus 16 orang BBLR, 25 orang asfiksia, 6 orang infeksi dan 26 orang lain-lainnya mengalami hipotrmi, kelainan congenital, aspirasi jalan nafas, premature, hidrosefalus) . ${ }^{(7)}$

Melihat kenyataan tersebut, maka pelayanan antenatal harus dilaksanakan secara konprehensif, terpadu dan berkualitas agar adanya masalah/ penyakit tersebut dapat dideteksi dan ditangani secara dini. Melalui pelayanan antenatal yang terpadu, Ibu hamil akan mendapatkan pelayanan yang lebih menyeluruh dan terpadu, sehingga hak reproduksinya dapat terpenuhi, Missed opportunity dapat dihindari serta pelayanan kesehatan dapat diselenggarakan secara lebih efektif dan efesien. ${ }^{(9)}$

Pelayanan Antenatal yang berkualitas harus dilakukan oleh sumber daya manusia yang handal dalam bidang asuhan pelayanan antenatal, bidan yang berkualitas yang mempu melaksanakan kegiatan antenatal sesuai dengan Standar Operational Prosedure yang sudah ditentukan. ${ }^{(9)}$

Pelayanan Kebidanan (Midwifery Service) adalah seluruh tugas yang menjadi tanggung jawab praktik profesi bidan dalam system pelayanan kesehatan yang bertujuan untuk meningkatkan kesehatan ibu dan anak dalam rangka mewujudkan kesehatan keluarga dan masyarakat. ${ }^{(9)}$

Secara sederhana, bidan memiliki peran dan fungsi sebagai seorang professional yang memberikan pelayanan kesehatan serta bertanggung jawab atas praktiknya. Dalam hal ini, wajar jika kemudian seorang bidan harus didukung dengan kompetensi inti bidan. Kompetensi inti yang dimaksud dalam hal ini adalah penguasaan pengetahuan dasar, sikap, dan keterampilan lapangan seorang bidan dalam melaksanakan praktik kebidanan secara aman dan bertanggung jawab sebagai pelayanan kesehatan. $^{(11)}$

Kinerja seorang bidan dapat dipengaruhi oleh faktor internal yaitu pendidikan, pelatihan, sikap, motivasi, lama bertugas, kecakapan, pengetahuan, dan keterampilan, dan faktor eksternal yaitu kelengkapan sarana, komitmen atasan, penerimaan lingkungan, struktur dan imbalan. ${ }^{(12)}$

Bidan merupakan profesi yang diakui secara nasional maupun international dengan 
sejumlah praktisi di seluruh dunia. Pegertian bidan dan bidang prakteknya secara internasional telah diakui oleh International Confederation of Midwives (ICM) tahun 1972 dan Intenational Federation of International Gynaecologist and Obstertritian (FIGO) tahun 1973, WHO dan Badan lainnya. ${ }^{(10)}$

Sumber Daya Manusia merupakan modal dan kekayaan yang terpenting dari setiap kegiatan manusia. Manusia sebagai unsur terpenting mutlak dianalisis dan dikembangkan dengan cara tersebut. Waktu, tenaga dan kemampuanya benar-benar dapat dimanfaatkan secara optimal bagi kepentingan organisasi, maupun bagi kepentingan individu (Fathoni, 2006). Pendekatan sumber daya manusia adalah peningkatan kualitas SDM yang dimulai sejak pembuahan, janin dalam kandungan, bayi, anak remaja dan Ibu. Oleh sebab itu pendekatan melalui peningkatan kesejahteraan Ibu dan anak merupakan pendekatan yang paling strategis. ${ }^{(13)}$

Dari uraian diatas dapat dilihat bahwa, walaupun Kota Padang telah memiliki banyak tempat pelayanan kesehatan bagi Ibu hamil, dan juga tenaga yang bisa memberi pelayanan kesehatan, tetapi kematian Ibu oleh karena persalinan masih cukup tinggi menurut beberapa penelitian penyebab dari kematian Ibu melahirkan dapat dicegah dengan mendapatkan pelayanan antenatal yang berkualitas. ${ }^{(8)}$.

\section{METODE PENELITIAN}

Penelitian ini merupakan penelitian dengan metode penelitian kuantitatif dengan desain cross sectional Waktu penelitian dimulai dari bulan Januari hingga bulan September tahun 2017. Pada penelitian ini teknik pengumpulan data pada penelitian kuantitatif adalah kuesioner untuk variabel pendidikan, pelatihan, sikap, motivasi, lama bertugas, komitmen atasan dan penerimaan lingkungan pada observasi dan wawancara untuk variabel pelayanan antenatal dan sarana dan prasarana.

Populasi pada penelitian ini adalah seluruh bidan yang bertugas di ruangan KIA di puskesmas rawatan kota padang. Teknik pengambilan sampel adalah total sampling dimana seluruh populasi dijadikan sampel.

\section{HASIL}

\section{Analisis Univariat}

a. Variabel Dependen

Tabel 1 Distribusi Frekuensi

Responden Berdasarkan Kualitas

Pelayanan Antenatal Tahun 2017

\begin{tabular}{|c|c|c|}
\hline Pelayanan Antenatal & $\mathrm{f}$ & $\%$ \\
\hline Tidak sesuai & 16 & 40 \\
\hline Sesuai & 24 & $\underline{60}$ \\
\hline Total & 40 & $\underline{100}$ \\
\hline
\end{tabular}

Dari tabel 1 terlihat bahwa $60 \%$ petugas yang melakukan layanan antenatal yang sesuai dengan standar.

\section{b. Variabel Independen \\ 1) Faktor Internal}

Tabel 2 Distribusi Frekuensi Responden Berdasarkan Faktor Internal (Pendidikan, Pelatihan, sikap, motivasi, lama bekerja) di Puskesmas Perawatan di Kota Padang Tahun 2017

\begin{tabular}{|c|c|c|}
\hline Karakteristik & $f(n=40)$ & $\%$ \\
\hline \multicolumn{3}{|l|}{ Pendidikan } \\
\hline Perawat Bidan & 13 & 32.5 \\
\hline Bidan & 27 & 67.5 \\
\hline \multicolumn{3}{|l|}{ Pelatihan } \\
\hline Tidak pernah & 24 & 60 \\
\hline Pernah & 16 & 40 \\
\hline \multicolumn{3}{|l|}{ Sikap } \\
\hline Kurang baik & 15 & 37.5 \\
\hline Baik & 25 & 62.5 \\
\hline \multicolumn{3}{|l|}{ Motivasi } \\
\hline Kurang & 20 & 50 \\
\hline Baik & 20 & 50 \\
\hline \multicolumn{3}{|l|}{ Lama bekerja } \\
\hline $\begin{array}{l}\text { Baru }(<2 \text { Tahun } \\
1 \text { bulan) }\end{array}$ & 16 & 40 \\
\hline $\begin{array}{l}\text { Lama ( } \geq 2 \\
\text { tahun } 1 \text { bulan) }\end{array}$ & 24 & 60 \\
\hline
\end{tabular}

Dari tabel 2. dapat dilihat bahwa petugas pelayanan antenatal Puskesmas rawatan di Kota Padang sebanyak $67.5 \%$ berpendidikan bidan. Petugas yang tidak pernah dapat pelatihan dalam waktu 2 tahun terakhir sebanyak $60 \%$. Petugas yang punya sikap baik sebanyak $62.5 \%$. Sebanyak $50 \%$ 
petugas mempunyai motivasi baik dalam melaksanakan pelayanan antenatal. Sebanyak $60 \%$ responden dengan lama kerja lebih dari 2 tahun 1 bulan sebagai petugas antenatal di ruangan KIA Ibu.

\section{2) Faktor Eksternal}

Tabel 3 Distribusi Frekuensi Responden Berdasarkan Faktor Eksternal (komitmen atasan dan penerimaan lingkungan) Tahun 2017

\begin{tabular}{|c|c|c|}
\hline \multirow{2}{*}{$\begin{array}{l}\text { Karakteristik } \\
\text { Komitmen atasan }\end{array}$} & \multirow[t]{2}{*}{$\mathrm{f}(\mathrm{n}=40)$} & \multirow[t]{2}{*}{$\%$} \\
\hline & & \\
\hline Kurang & 26 & 65 \\
\hline Baik & 14 & 35 \\
\hline Penerimaan & & \\
\hline lingkungan & & \\
\hline Kurang & 25 & 62,5 \\
\hline Baik & 15 & $\underline{37,5}$ \\
\hline
\end{tabular}

Berdasarkan tabel 5.3 dapat dilihat bahwa komitmen atasan yang komitmennya kurang baik sebanyak 65\%. dan Sebesar $62.5 \%$ responden memiliki penerimaan baik dengan lingkungan.

\section{Analisa Bivariat}

\section{a. Faktor Internal dengan Pelayanan Antenatal 1) Pendidikan}

Tabel 4 Hubungan Pendidikan Bidan dengan Pelayanan Antenatal oleh Bidan di Puskesmas Rawatan Kota Padang Tahun 2017

\begin{tabular}{|c|c|c|c|c|c|c|c|}
\hline \multirow{3}{*}{ Pendidikan } & \multicolumn{4}{|c|}{ Pelayanan Antenatal } & \multirow{2}{*}{\multicolumn{2}{|c|}{ Total }} & \multirow{3}{*}{$\begin{array}{l}\mathrm{P} \\
\text { value }\end{array}$} \\
\hline & \multicolumn{2}{|c|}{$\begin{array}{l}\text { Tidak } \\
\text { Sesuai }\end{array}$} & \multicolumn{2}{|c|}{ Sesuai } & & & \\
\hline & $\mathrm{f}$ & $\%$ & $\mathrm{f}$ & $\%$ & $\underline{\mathrm{f}}$ & $\%$ & \\
\hline Perawat & 7 & $\overline{53.8}$ & 6 & 46.2 & 13 & 100 & \\
\hline Bidan & & & & & & & 0.370 \\
\hline Bidan & 9 & 33.3 & 18 & 66.7 & 27 & 100 & \\
\hline Total & $\underline{16}$ & 40.0 & 23 & $\underline{60.0}$ & $\underline{40}$ & 100 & \\
\hline
\end{tabular}

Dari tabel 4 didapatkan informasi bahwa bidan yang melakukan pelayanan antenatal tidak sesuai standar lebih banyak pada pendidikan perawat bidan $(53,8 \%)$ dibandingkan dengan yang bidan (D3) $(33.3 \%)$. Karena inilah kita mengetahui bahwa tidak ada hubungan antara pendidikan dengan pelayanan antenatal $(\mathrm{p}$ value $=$
$0.370)$.

\section{2) Pelatihan}

Tabel 5 Hubungan Pelatihan yang Pernah Diikuti oleh Bidan 2 Tahun Terakhir dengan Pelayanan Antenatal oleh Bidan di Puskesmas Rawatan Kota Padang Tahun 2017

\begin{tabular}{|c|c|c|c|c|c|c|c|}
\hline \multirow{3}{*}{ Pelatihan } & \multicolumn{4}{|c|}{ Pelayanan Antenatal } & \multirow{2}{*}{\multicolumn{2}{|c|}{ Total }} & \multirow{3}{*}{$\begin{array}{l}P \\
\text { value }\end{array}$} \\
\hline & \multicolumn{2}{|c|}{$\begin{array}{l}\text { Tidak } \\
\text { Sesuai }\end{array}$} & \multicolumn{2}{|c|}{ Sesuai } & & & \\
\hline & $\mathrm{f}$ & $\%$ & $\mathrm{f}$ & $\%$ & $\mathrm{f}$ & $\%$ & \\
\hline Tidak & 8 & 33.3 & 16 & 66.7 & 24 & 100 & \\
\hline Pernah & & & & & & & 0.469 \\
\hline Pernah & 8 & $\underline{50}$ & 8 & $\underline{50}$ & 16 & 100 & \\
\hline Total & 16 & 40.0 & 23 & 60 & 40 & 100 & \\
\hline
\end{tabular}

bahwa bidan yang melakukan pelayanan antenatal yang tidak sesuai standar lebih banyak pada bidan yang pernah mengikuti pelatihan $(50 \%)$ dibandingkan dengan bidan yang tidak pernah mengikuti pelatihan (33.3\%). Karena inilah kita mengetahui bahwa tidak ada hubungan antara pelatihan dengan pelayanan antenatal ( $\mathrm{p}$ value $=$ 0.469 ).

\section{2) Sikap}

Tabel 6 Hubungan Sikap Bidan dengan

Pelayanan Antenatal oleh Bidan di

Puskesmas Rawatan Kota Padang Tahun

2017

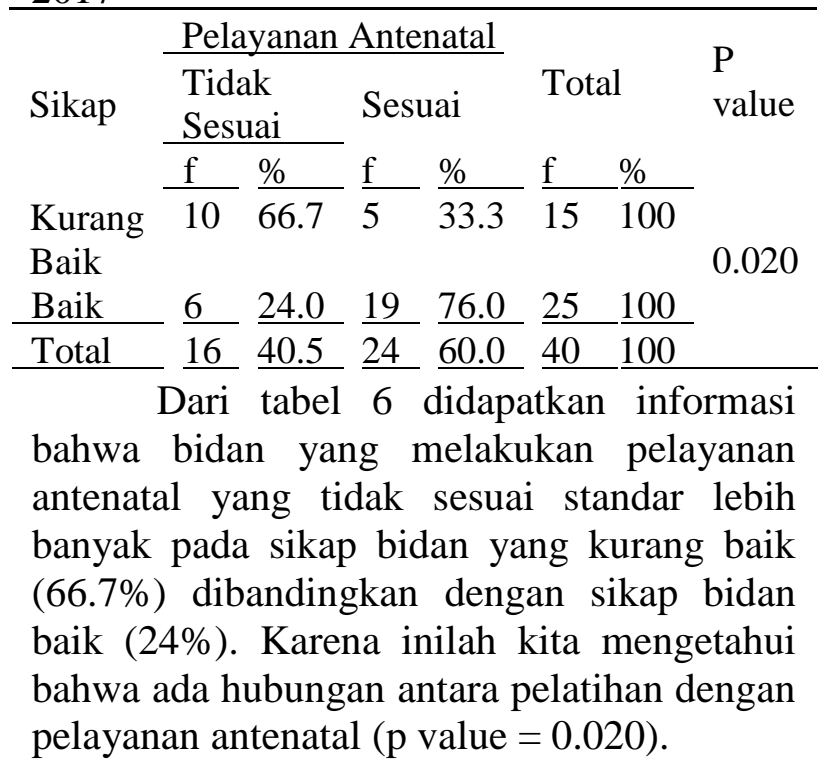

\section{3) Motivasi}

Tabel 7 Hubungan Motivasi Bidan dengan 
Pelayanan Antenatal oleh Bidan di Puskesmas Rawatan Kota Padang Tahun 2017

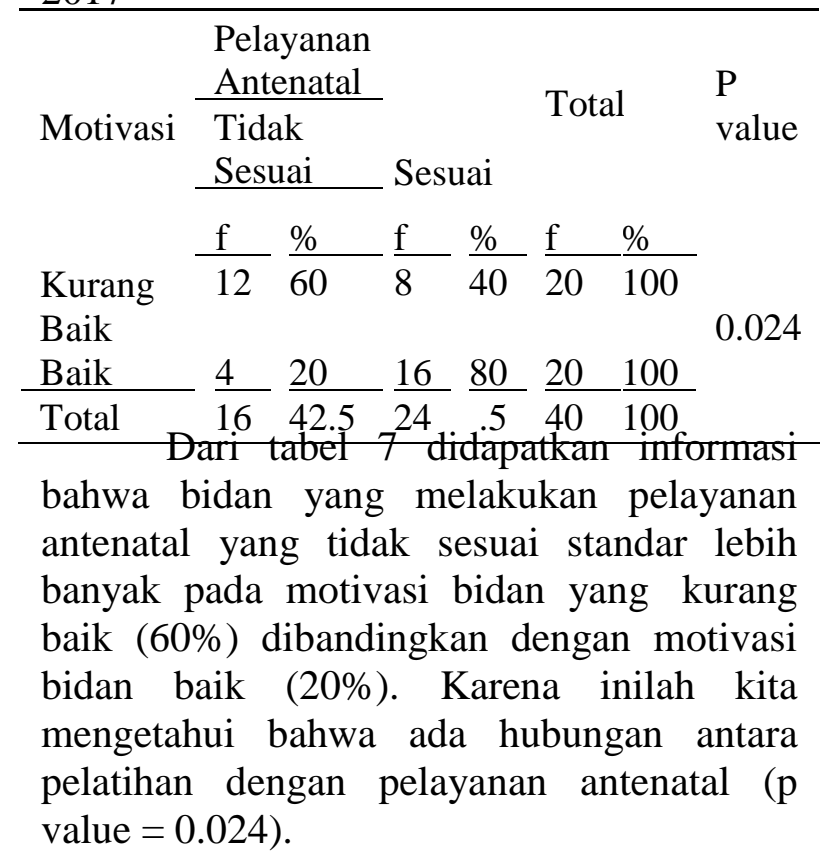

\section{4) Lama bekerja}

Tabel 8 Hubungan Lama Kerja Bidan dengan Pelayanan Antenatal di Puskesmas

Rawatan Kota Padang Tahun 2017

\begin{tabular}{|c|c|c|c|c|c|c|}
\hline \multirow{3}{*}{$\begin{array}{l}\text { Lama } \\
\text { Kerja }\end{array}$} & \multicolumn{3}{|c|}{$\begin{array}{l}\text { Pelayanan } \\
\text { Antenatal }\end{array}$} & \multirow{2}{*}{\multicolumn{2}{|c|}{ Total }} & \multirow{3}{*}{$\begin{array}{l}P \\
\text { value }\end{array}$} \\
\hline & $\begin{array}{l}\text { Tidak } \\
\text { Sesuai }\end{array}$ & \multicolumn{2}{|c|}{ Sesuai } & & & \\
\hline & $\mathrm{f} \quad \%$ & f & $\%$ & $\mathrm{f}$ & $\%$ & \\
\hline Baru & 25 & 12 & 75 & 16 & 100 & 211 \\
\hline Lama & $12 \underline{50}$ & 12 & $\underline{50}$ & $\underline{24}$ & 100 & 0.211 \\
\hline Total & $16 \quad 40$ & 23 & $\underline{60}$ & $\underline{40}$ & 100 & \\
\hline
\end{tabular}

Dari tabel 8 didapatkan informasi bahwa bidan yang melakukan pelayanan antenatal yang tidak sesuai standar lebih banyak pada lama kerja bidan yang lama (55\%) dibandingkan dengan lama kerja bidan baru (25\%). Karena inilah kita mengetahui bahwa tidak ada hubungan antara lama bekerja dengan pelayanan antenatal $(\mathrm{p}$ value $=0.211)$.

\section{b. Faktor Eksternal dengan Pelayanan Antenatal}

1) Komitmen Atasan

Tabel 9 Hubungan Komitmen Atasan dengan Pelayanan Antenatal yang Dilakukan Bidan di Puskesmas Rawatan Kota Padang Tahun 2017

\begin{tabular}{llll}
\hline $\begin{array}{lll}\text { Komitmen } \\
\text { Atasan }\end{array}$ & \multicolumn{2}{l}{ Pelayanan Antenatal } \\
\cline { 1 - 1 } & Tidak & Sesuai & $\mathrm{p}$ \\
& &
\end{tabular}

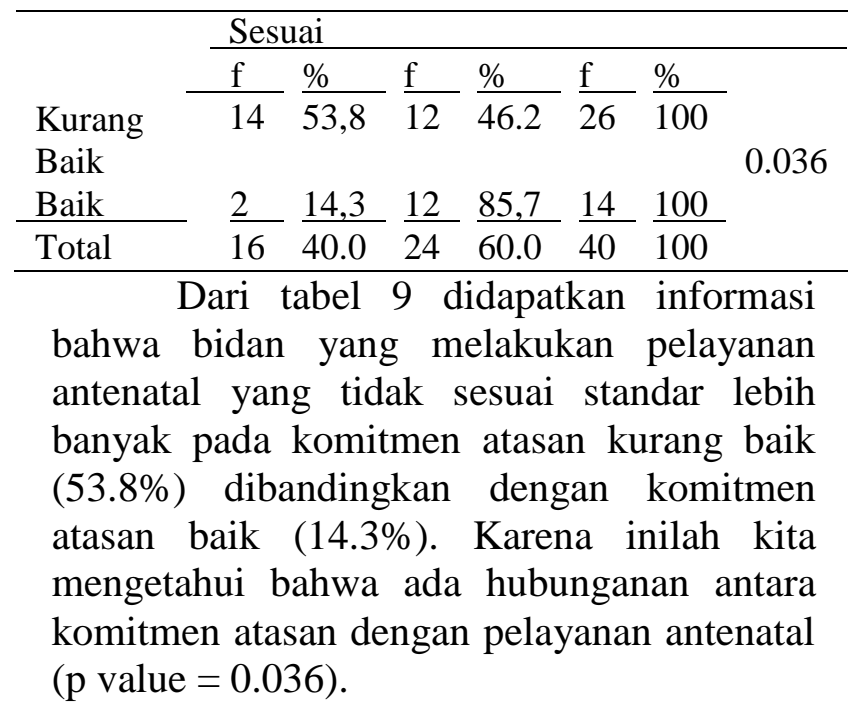

2) Penerimaan Lingkungan

Tabel 10 Hubungan Penerimaan Lingkungan dengan Pelayanan Antenatal Dilakukan Bidan di Puskesmas Perawatan Kota Padang Tahun 2017

\begin{tabular}{|c|c|c|c|c|c|c|c|}
\hline \multirow{3}{*}{$\begin{array}{l}\text { Penerima } \\
\text { an Lingk }\end{array}$} & \multicolumn{4}{|c|}{ Pelayanan Antenatal } & \multirow{2}{*}{\multicolumn{2}{|c|}{ Total }} & \multirow{3}{*}{$\begin{array}{l}\mathrm{P} \\
\text { value }\end{array}$} \\
\hline & \multicolumn{2}{|c|}{$\begin{array}{l}\text { Tidak } \\
\text { Sesuai }\end{array}$} & \multicolumn{2}{|c|}{ Sesuai } & & & \\
\hline & $\mathrm{f}$ & $\%$ & $\mathrm{f}$ & $\%$ & $\mathrm{f}$ & $\%$ & \\
\hline Kurang & 1 & 56.0 & 11 & 44.0 & 25 & 100 & \\
\hline Baik & 4 & & & & & & 0.020 \\
\hline Baik & 2 & 13.3 & 13 & 86.7 & 15 & 100 & \\
\hline Total & $\begin{array}{l}1 \\
6\end{array}$ & 40.0 & 24 & 60.0 & 40 & 100 & \\
\hline
\end{tabular}

Dari tabel 10 didapatkan informasi bahwa bidan yang melakukan pelayanan antenatal yang tidak sesuai standar lebih banyak pada penerimaan lingkungan kurang baik $(56 \%)$ dibandingkan dengan penerimaan lingkungan baik (13.3\%). Karena inilah kita mengetahui bahwa ada hubungan antara penerimaan lingkungan dengan pelayanan antenatal $(\mathrm{p}$ value $=0.020)$.

\section{c. Analisis Multivariat}

Analisis yang dilakukan adalah analisis regresi logistik berganda bentuk reduced model dengan Backward Stepwise (LR) metode dengan efek utama maka terpilih 5 variabel setelah dikontrol dengan variabel lain yaitu variabel pendidikan, sikap, lama bertugas, komitmen atasan dan penerimaan lingkungan.

Pada tabel dibawah ini terlihat bahwa terdapat 4 variabel yang didapatkan dari 
analisis ini bermakna $\mathrm{p}<0.05$.

Tabel 12. Regresi Logistik Berganda

\begin{tabular}{|c|c|c|c|c|}
\hline Variabel & SE & Wald & $\underline{\text { Sig }}$ & $\underline{\operatorname{Ekp} \beta}$ \\
\hline Pendidikan & 1.537 & 4.439 & 0.035 & 0.039 \\
\hline Sikap & 1.267 & 5.751 & 0.016 & 20.896 \\
\hline Komitmen & 1.304 & 3.855 & 0.050 & 12.938 \\
\hline Atasan & 1.608 & 7.680 & 0.006 & 86.270 \\
\hline \multicolumn{5}{|l|}{ Penerimaan } \\
\hline Lingkung & & & & \\
\hline
\end{tabular}

Dari tabel 12 diatas dapat dilihat 4 variabel yang bermakna $(\mathrm{p}<0.05)$. Pada 4 variabel tersebut variabel yang paling berhubungan dengan pelayanan antenatal adalah penerimaan lingkungan dengan nilai $\mathrm{p}$ value 0.006 .

\section{PEMBAHASAN}

Pelayanan antenatal adalah pelayanan kesehatan yang diberikan kepada ibu selama masa kehamilannya sesuai dengan standar pelayanan antenatal yang mencakup anamnesis, pemeriksaan fisik umum dan kebidanan, pemeriksaan laboratorium atas indikasi tertentu serta indikasi dasar dan khusus

Tujuan asuhan antenatal adalah memantau kemajuan kehamilan untuk memastikan kesehatan ibu dan tumbuh kembang bayi, meningkatkan dan mempertahankan kesehatan fisik, mental dan social ibu dan bayi, mengenali secara dini adanya ketidaknormalan atau komplikasi yang mungkin selama kehamilan, termasuk riwayat penyakit secara umum, kebidanan dan pembedahan, mempersiapkan persalinan cukup bulan, melahirkan dengan selamat,ibu maupun bayinya dengantrauma seminimal mungkin, mempersiapkan ibu agar masa nifas berjalan normal dan pemberian ASI eksklusif, mempersiapkan peran ibu dan keluarga dalam menerimakelahiran bayi agar dapat tumbuh kembang secara normal serta optimalisasi kembalinya kesehatan reproduksi ibu secara wajar. Keuntungan layanan antenatal sangat besar karena dapat mengetahui resiko dan komplikasi sehingga ibu hamil dapat diarahkan untuk melakukan rujukan ke rumah sakit. Layanan antenatal dilakukan sehingga dapat dilakukan pengawasan yang lebih intensif, pengobatan agar resiko dapat ikendalikan, serta melakukan rujukan untuk mendapat tindakan yang adekuat. ${ }^{(14)}$

Pelayanan yang dilakukan secara rutin juga merupakan upaya untuk melakukan deteksi dini kehamilan beresiko sehingga dapat dengan segera dilakukan tindakan yang tepat untuk mengatasi dan merencanakan serta memperbaiki kehamilan tersebut. Kelengkapan antenatal terdiri dari jumlah kunjungan antenatal dan kualitas pelayanan antenatal. ${ }^{(15)}$

Hasil penelitian ini menunjukkan bahwa lebih dari separo responden bidan di Puskesmas Rawatan Kota Padang telah melaksanakan pelayanan antenatal sesuai dengan standar. Pelayanan antenatal sesuai dengan standar yang telah ditentukan akan mempengaruhi kesehatan ibu hamil dan bayi yang dilahirkan, sehingga semakin baik pelayanan antenatal diharapkan angka kematia ibu juga akan semakin menurun.

Diharapkan seluruh bidan pelaksana pelayanan antenatal di Puskesmas Perawatan di Kota Padang untuk selalu melaksanakan pelayanan antenatal kepada ibu hamil sesuai dengan standar yang telag ditetapkan oleh pemerintah, sehingga derajat kesehatan ibu hamil akan semakin meningkat.

Standar pelayanan kebidanan adalah rumusan tentang penampilan atau nilai diinginkan yang mampu dicapai, berkaitan dengan parameter yang telah ditetapkan. Standar pelayanan kebidanan berisi langkahlangkah pokok yang berlu diikuti oleh bidan dalam memberikan asuhan. Dalam kurikulum D III kebidanan, standar pelayanan kebidanan sudah merupakan materi pokok yang harus dikuasai oleh mahasiswa kebidanan.

Pendidikan normal yang dirancang dan diselenggarakan oleh pemerintah maupun swasta dengan dukungan IBI adalah program D III dan DIV Kebidanan. Perwat bidan hanya dibuka sudah sangat lama, untuk meningkatkan mutu bidan untuk saat ini pendidikan perawat bidan tidak dilaksanakan lagi.

Sedangkan menurut Kaswan (16) pelatihan adalah suatu proses meningkatkan 
pengetahuan dan keterampilan karyawan. Pelatihan mungkin juga meliputi pengubahan sikap sehingga karyawan dapat melakukan pekerjaannya lebih efektif. Pelatihan juga dapat dilakukan pada semua tingkat organisasi.

Untuk mencapai tujuan pelatihan ada beberapa hal yang harus diperhatikan antara lain tidak adanya seleksi peserta pelatihan dan kurangnya motivasi dari peserta bisa menyebabkan tujuan pelatihan tidak tercapai. Pelaksanaan pelatihan yang kurang baik, seperti memperpendek waktu pelatihan dan mendatangkan narasumber yang tidak potensial juga akan mempengaruhi hasil pelatihan.

Perlu adanya pelatihan yang sesuai dengan bidang dari bidan tersebut, seperti untuk bidan yang ada di ruangan KIA ibu harus mendapatkan pelatihan yang berfokus pada pelayanan antenatal yang sesuai dengan standar, Sehingga bidan akan lebih paham dalam melaksanakan tidakan antenatal kepada ibu hamil.

Petugas layanan antenatal mempunyai sikap yang baik terhadap pelayanan antenatal yang sesuai dengan standar, artinya mereka meyakini bahwa standar yang sudah ada memang perlu dipakai dalam memberikan pelayanan antenatal. Hasil penelitian ini menunjukkan bahwa sikap bidan terhadap layanan antenatal berpengaruh terhadap tindakan bidan dalam melaksanakan pelayanan antenatal.

Hasil ini dapat dijelaskan dengan teori bahwa perilaku merupakan resultante dari faktor internal dan eksternal seseorang yang bila diukur satu persatu belum tentu memperlihatkan perilaku dari orang tersebut. Dengan demikian seorang yang bersikap positif terhadap layanan yang sesuai dengan standar, dengan kuatnya pengaruh faktorfaktor lain, sehingga sikap tidak muncul sebagai tindakan.

Motivasi menurut Moenir

motivasi adalah ransangan dari luar dalam bentuk benda atau bukan benda yang dapat menumbuhkan dorongan pada orang untuk memiliki, menikmati, menguasai, atau mencapai benda/ bukan benda tersebut.
Motif sering diartikan dengan istilah dorongan. Dorongan atau tenaga tersebut merupakan gerak jiwa dan jasmani untuk berbuat. Jadi motif tersebut merupakan driving force yang menggerakkan manusia untuk bertingkah laku, dan di dalam perbuatan itu mempunyai tujuan tertentu.

Motivasi tidak terlepas dari kebutuhan dan keinginan yang perlu direspons, sehingga motivasi sangat erat kaitannya dengan kebutuhan dan keinginan dari dalam diri. Semakin tinggi kebutuhan dan keinginan dalam diri maka semakin tinggi juga motivasi dari dalam diri akan muncul.

Pada penelitian ini tidak bisa dibuktikan bahwa petugas yang sudah lama bekerja akan melaksanakan pelayanan antenatal yang sesuai dengan standar lebih sesuai dengan standar dibandingkan dengan petugas yang belum lama bekerja. Ini mungkin bisa diterangkan bahwa pada kenyataan yang dilihat di lapangan petugas yang sudah lama bekerja cenderung sudah berkurang minat mereka untuk membaca atau mengikuti kegiatan yang menyangkut pengembangan profesi mereka, seperti seminar yang diadakan oleh organisasi bidan, sehingga mereka tidak mendapatkan masukan baru tentang kemajuan pelayanan antenatal.

Menurut Siagian (18) kepemimpinan atasan adalah inti dari managemen karena kepemimpinan adalah motor penggerak bagi sumber daya manusia dan sumber daya alam. Komitmen atasan yang perlu pada pelayanan antenatal adalah dalam hal kelengkapan sarana serta bimbingan dan supervisi. Supervisi adalah suatu upaya pengarahan yang dilakukan antara lain dengan mendengarkan keluhan tentang pelaksanaan kegiatan atau memberikan petunjuk serta saran dalam mengatasi permasalahan yang dihadapi pelaksana.

Hasil penelitian menunjukkan komitmen atasan yang kurang baik lebih banyak dibandingkan dengan yang baik. Komitmen atasan yang baik akan membuat kinerja bidan juga akan baik karena komitmen atasan yang baik akan terciptanya setiap pekerjaan sesuai dengan SOP yang 
telah ditentukan.

Untuk penerimaan masyarakat terhadap petugas layanan antenatal ini bisa dikatakan bahwa petugas bisa berinteraksi dengan masyarakat di luar dan baik hubungan di tempat kerja, sehingga mereka memilih pelayanan yang diberikan oleh petugas Puskesmas dan unit-unitnya. Hasil penelitian ini menegaskan bahwa penerimaan lingkungan yang baik akan mendorong bidan melaksanakan pelayanan antenatal sesuai standar.

\section{SIMPULAN}

1. Lebih dari separo responden telah melaksanakan layanan antenatal sesuai standar

2. Lebih dari separo responden berpendidikan bidan, tidak pernah mendapatkan pelatihan, bersikap baik terhadap pelayanan antenatal, lama kerja lama, separoh responden memiliki motivasi baik terhadap pelayanan antenatal,

3. Lebih dari separo responden dengan penerimaan lingkungan baik, dan mengatakan komitmen atasan baik.

4. Tidak terdapat hubungan yang bermakna antara pedidikan bidan, pelatihan, dan lama bertugas dengan pelayanan antenatal dan terdapat hubungan yang bermakna antara sikap,motivasi dengan pelayanan antenatal

5. Terdapat hubungan yang bermakna antara komitmen atasan dan penerimaan lingkungan dengan pelayanan antenatal.

6. Penerimaan lingkungan merupakan variabel yang paling berhubungan terhadap pelayanan antenatal sesuai dengan standar, diikuti oleh penerimaan lingkungan dan komitmen atasan

\section{UCAPAN TERIMAKASIH}

Terimakasih peneliti ucapkan kepada Dinas Kesehatan Kota Padang, seluruh Puskesmas Kota Padang serta seluruh Bidan yang telah membantu proses penelitian, dimulai dari pengambilan data awal sampai kepada proses perbaikan hasil penelitian.

\section{REFERENSI}

Kementrian Kesehatan Republik Indonesia. 2010 Rencana Strategis Kementrian Kesehatan Tahun 2010-2014. Jakarta

Dinas Kesehatan Kota Padang. 2017. Profil Kesehatan Kota Padang. Padang Tahun 2016. Padang

Dinas Kesehatan Kota Padang. 2014. Laporan Tahunan Dinas Kesehatan Kota Padang Tahun 2013. Padang

Pusdiknakes - WHO - JHPIEGO. 2003.Panduan Pengajaran Asuhan Kebidanan Fisiologis Bagi Doses Diploma III Kebidanan, Buku 2 Asuhan Antenatal. Pusat tenaga kesehatan departemen kesehatan dan kesejahteraan sosial.Jakarta

Kementrian Kesehatan Republik Indonesia. 2015. Profil Kesehatan Indonesia Tahun 2014. Jakarta

Kementrian Kesehatan Republik Indonesia .2012 - 2014. Data dan Informasi Kesehatan Indonesia . Jakarta

Dinas Kesehatan Provinsi Sumatra Barat. 2015 . Profil Dinas Kesehatan Provinsi Sumatra Barat Tahun 2014. Padang

Dinas Kesehatan Kota Padang. 2013. Laporan Tahunan Dinas Kesehatan Kota Padang Tahun 2012. Padang

Kementrian Kesehatan Republik Indonesia. 2012. Standar Pelayanan Minimal (SPM) Kabupaten dan Kota.Jakarta

Sujianti \& Susanti. 2009. Buku ajar Konsep Kebidanan. Nuha medika. Yogyakarta

Zian Farodis. Panduan Lengkap Manajemen Kebidanan. 2012. Banguntapan Yogyakarta. D - Medika.

Gibson,J. L. Organisasi Perilaku, Struktur dan Proses (Terjemahan). 2009. Erlangga. Jakarta

Dinas Kesehatan Kota Padang. 2010. Profil Kesehatan Kota Padang. Padang Tahun 2009. Padang

Manuaba, I B I. 1998. Ilmu Kebidanan. Penyakit Kandungan dan KB untuk Pendidikan Bidan. EGC . Bandung 
Istiarti T. 2000. Kaitan antara Kemiskinan dan Kesehatan. Media Pressindo.

Yogyakarta.

Kaswan. 2011. Pelatihan dan Pengembangan untuk Meningkatkan Kinerja SDM. Alfabeta. Bandung

Moenir.2006. Manajemen PelayananUmum di Indonesia. Bumi Aksara.Jakarta

Siagan, SP. 1996. Teori motivasi dan aplikasinya. Rineka cipta. Jakarta 